\title{
EDUKASI TRI HITA KARANA DALAM PERTUNJUKAN DRAMA GONG PENOPANG KEBERLANJUTAN BUDAYA BALI
}

\author{
I Wayan Sugita \\ Universitas Hindu Negeri I Gusti Bagus Sugriwa Denpasar \\ Email: wayansugita2@gmail.com
}

\begin{abstract}
This article aims to discuss the education of Tri Hita Karana (THK) in the drama gong performance in the era of society 5.0 and its meaning for the sustainability of Balinese culture. This article is the result of a qualitative study whose data were collected through observation, document studies, and in-depth interviews with performers and representatives of the audience of drama gong, as well as observers of Balinese arts and culture. Qualitative descriptive analysis was carried out by applying semiotic theory, symbolic interactionism theory, and social action theory (Bourdieu). The results of the study show that traditional Balinese performing arts function as a medium of entertainment and education of Balinese culture, especially about the philosophy of THK to its fans. Through three drama gong stories, namely "Jayaprana", "Ni Diah Tantri" and "Cupak Madeg Ratu" have succeeded in entertaining as well as delivering education on THK, so that Balinese people are able to realize a harmonious life: between humans and God (parahyangan), humans with each other (pawongan), and humans with nature (palemahan). THK education through drama gong performances has a meaning in strengthening traditions and sustaining the cultural sustainability of the Balinese Hindu community.
\end{abstract}

Keywords: education, Tri Hita Karana, drama gong, sustainability of Balinese culture

\begin{abstract}
ABSTRAK
Artikel ini bertujuan membahas edukasi Tri Hita Karana (THK) dalam pertunjukan drama gong pada era society 5.0 dan maknanya bagi keberlanjutan budaya Bali. Artikel ini merupakan hasil penelitian kualitatif yang datanya dikumpulkan melalui observasi, studi dokumen dan wawancara mendalam dengan pelaku seni dan wakil penonton drama gong, serta pemerhati seni-budaya Bali. Analisis deskriptif kualitatif dilakukan dengan menerapkan teori semiotika, teori interasionisme simbolik, dan teori tindakan sosial (Bourdieu). Hasil penelitian menunjukkan bahwa seni pertunjukan tradisional Bali berfungsi sebagai media hiburan dan media edukasi budaya Bali, khususnya tentang filosofi THK kepada penggemarnya. Melalui tiga kisah drama gong, yakni "Jayaprana", "Ni Diah Tantri" dan "Cupak Madeg Ratu" telah berhasil menghibur sekaligus menyampaikan edukasi THK, agar masyarakat Bali mampu mewujudkan kehidupan yang harmonis: antara manusia dengan Tuhan (parahyangan), manusia dengan sesamanya (pawongan), dan manusia dengan alam (palemahan). Edukasi THK melalui pertunjukan drama gong memiliki makna dalam memperkuat tradisi dan menopang keberlanjutan budaya masyarakat Hindu Bali.

Kata Kunci: edukasi, Tri Hita Karana, drama gong, keberlanjutan budaya Bali
\end{abstract}




\section{PENDAHULUAN}

"Bangunlah jiwanya, bangunlah badannya". Inilah bagian dari bait lagu kebangsaan "Indonesia Raya". Membangun jiwa terlebih dahulu, baru membangun fisik (tubuh) agar manusia yang sehat lahir batin, jasmani-rohani. Pembangunan manusia Indonesia seutuhnya adalah pembangunan yang bukan hanya mengejar kecerdasan otak semata, tetapi membangun manusia yang memilliki jiwa spiritual dan berbudi pekerti. Manusia seutuhnya juga dapat diartikan memiliki jati diri dan berkepribadian utuh, sehat jasmani dan rohaninya (Ruastiti, 2020).

Dalam upaya membangun manusia Indonesia sutuhnya tersebut, seni dan budaya menjadi penting. Dalam kaitan ini, Prof Ida Bagus Mantra (dalam Sadiartha, 2016) menghendaki agar Bali dibangun dengan kepribadian. Kepribadian yang dimaksud adalah Bali memiliki budaya berupa kesenian berlandasakan Agama Hindu. Hubungan Agama Hindu dengan seni tidak dapat dipisahkan, karena ajaran agama dapat menumbuhkan rasa seni yang sangat mendalam di masyarakat. Seni yang dimaksudkan di sini bukanlah seni dalam arti sempit, tetapi estetika. Estetika adalah keindahan yang mendorong manusia untuk berkreasi, dinamis dalam sikapnya untuk mencapai kepuasan batin dan mempertajam institusinya. Manusia dapat maju dan dihormati bila menunjukkan kreativitas yang tinggi (Mantra, 1996).

Sebagai bagian dari masyarakat Nusantara, masyarakat Hindu Bali memiliki senibudaya yang beragam. Oleh karenanya, Kepariwisataan Budaya Bali adalah kepariwisataan Bali yang berlandaskan kepada Kebudayaan Bali yang dijiwai oleh filosofi Tri Hita Karana yang bersumber dari nilai-nilai budaya dan kearifan lokal Sad Kerthi serta berbasis taksu Bali (Perda No. 5 Tahun 2020, Pasal 1, ayat 12).

Sebagai bagian dari seni-budaya Bali, esksistensi drama gong memang sedemikian penting untuk menguatkan identitas budaya masyarakat Bali. Namun keberadaan seni budaya kini sedang diuji (bersaing) dengan budaya global. Keberadaan seni budaya daerah khususnya drama gong harus tetap dipertahankan yang pada masa kini cenderung kalah bersaing dengan aneka hiburan zaman modern seperti musik, film, dan online games yang tersedia di jaringan dunia maya (internet) begitu melimpah dan mudah diakses oleh siapa saja, termasuk oleh generasi muda Bali. Anak-anak muda Bali kini kurang tetarik dengan seni tradisional Bali, termasuk drama gong. Mereka lebih menyukasi aneka hiburan modern yang bisa diakses melalui gadget (handphone).

Agar seni pertunjukan drama gong tetap eksis, terus berkembang mengikuti tantangan zaman, beberapa Sanggar seni-budaya di Bali, termasuk Sanggar Kayon Gianyar, Sanggar Sekdut dan Sanggar Seni Puspa Kencana (SSPK) Denpasar - melakukan inovasi seni pertunjukan drama gong. Seni pertunjukan drama gong direvitalisasi sesuai tuntutan era revolusi industri 4.0 dan era Society 5.0 dengan mengikutsertakan generasi milenial Bali (kelahiran 1977- ke atas). Sesuai perkembangan teknologi digital, model drama gong inovatif sengaja dikemas sedemikian rupa dan bisa dinikmati melalui melalui saluran TV dan kanal Youtube (Sugita, 2021).

Inovasi drama gong di era digital dewasa ini diharapkan mampu mengangkat kembali kejayaan seni pertunjukan rakyat Bali ini seperti era keemasannya dalam dekade 1970 dan 1980-an di masa silam. Masa keemasan drama gong ini setidaknya ditandai oleh tiga hal: drama gong menemukan bentuknya sebagai seni drama berdialog dengan iringan gamelan gong gebyar; drama gong merajai panggung-panggung pentas kesenian di seluruh Bali dan para pemain utamanya diberlakukan seperti selebritis; dan gengsi drama gong di mata masyarakat Bali mengalahkan semua bentuk seni pertunjukan tradisi Bali lainnya (Dibia, 2012).

Sebagai seni pertunjukan rakyat Bali, drama gong mampu hadir sebagai tontonan (hiburan) sekaligus tuntunan (media pendidikan). Drama gong bisa diposisikan sebagai guru 
dan peserta didik diidentikkan dengan penonton mewakili masyarakat. Posisi drama gong sebagai guru rupanya tidak berlebihan mengingat dalam budaya Bali, dalang wayang kulit sering dijuluki sebagai "guru loka" atau guru masyarakat. Dalam penyampaian pesan, seorang dalang tidak berbeda dengan pemain drama gong. Baik dalang maupun pemain drama gong sama-sama menyampaikan pesan, bahkan juga kritik sosial yang dibungkus dengan lelucon atau melalui dialog-dialognya (Sugita, 2017).

Secara umum, drama Gong memiliki dua fungsi, yaitu fungsi primer dan fungsi sekunder. Fungsi primer drama gong adalah sebagai sarana hiburan untuk masyarakat baik dalam upacara-upacara agama atau acara-acara khusus. Selanjutnya fungsi sekunder drama gong adalah sebagai media komunikasi massa, sebagai pengikat solidaritas masyarakat, sebagai media program pemerintah, dan sebagai fungsi pertunjukan (Widagama, 2017).

Seni pertunjukan tradisional drama gong bisa dijadikan media untuk menyampaikan kritik sosial dan sosialisasi pembangunan, termasuk yang terkait dengan pembangunan pariwisata Bali. Kritik sosial dan sosialisasi pembangunan ini disampaikan dengan nada humor melalui tokoh, pemain atau punokawan drama gong (Sugita, 2020, Setyawan, 2011). Humor drama gong menyulut gelak tawa penontonnya. Tawa diperlukan oleh manusia guna keseimbangan jiwanyanya yaitu melampiaskan perasaan tertekan melalui cara riang dan dapat dinikmati (Hasan, 1980). Tertawa mampu "menjernihkan dan menjelaskan", menghadirkan keriangan, serta menghilangkan kesepian dan keterasingan (Kartadjirja, 1973).

Drama gong telah menjadi media edukasi budaya Bali, termasuk edukasi tentang Bahasa Bali. Melalui tokoh yang dikisahkan dan punokawan, kritik sosial dan pesan-pesan terkait dinamika pembangunan di Bali terus disampaikan. Dalam beberapa tahun terakhir, drama gong sering mensosialisasikan filosofi Tri Hita Karana. Tri Hita Karana (THK) adalah tiga hal penyebab kesejahteraan atau kebahagiaan. Tiga hal tersebut adalah hubungan harmonis antara manusia dengan Tuhan Yang Maha Esa (parahyangan), manusia dengan manusia (pawongan) dan manusia dengan alam (palemahan). THK menurut Agama Hindu merupakan sikap hidup harmoni antara percaya dan bhakti kepada Tuhan, mengabdi kepada sesama manusia, dan menyayangi alam berdasarkan yadnya (Mantra, 1996).

THK) merupakan nilai budaya yang mendasari berbagai aspek kehidupan masyarakat Bali, termasuk dalam lapangan kehidupan pertanian, pariwisata dan senibudaya. Artikel ini membahas (1) Bagaimana edukasi THK dalam pertunjukan drama gong inovatif pada era Society 5.0? (2) Apa makna edukasi THK drama gong tersebut bagi keberlanjutan budaya Bali?.

\section{PEMBAHASAN}

\subsection{Edukasi Tri Hita Karana dalam Pertunjukan Drama Gong Era Society 5.0}

Peradaban manusia kini memasuki era digital (revolusi industri 4.0) dan society 5.0. Era revolusi industri 4.0 ditandai dengan banyaknya sumber informasi melalui kanal media sosial, seperti Facebook, Youtube, Instagram, dan serta berkembangnya digitalisasi dan otomatisasi (I-Scoop, 2018). Pesatnya kemajuan sarana teknologi, perlu dibarengi dengan kesiapan masyarakat pengguna teknologi digital tersebut. Dalam kaitan ini, sejak tahun 2016 Pemerintah Jepang sudah memperkenalkan model masyarakat pintar (Society 5.0), di mana teknologi digital diaplikasikan dan berpusat pada kehidupan manusia. Manusia semestinya tidak diperbudak oleh teknologi, tetapi justru teknologi bisa dimanfaatkan secara cerdas untuk membantu pekerjaan manusia yang lebih efektif, efisien dan produktif. Pada era society 5.0, teknologi digital perlu dimanfaatkan sebagai media pendidikan dan alat untuk kemajuan serta kesejahteraan hidup manusia (Nastiti, 2020).

Model drama gong inovatif masa kini sengaja dikembangkan dengan mengikuti perkembangan teknologi di era digital (4.0) dan society 5.0. Eksistensi drama gong sampai 
dekade 2000-an telah mengalami berbagai inovasi. Inovasi drama gong mencakup: (1) kemasan cerita; (2) regenerasi pemain dengan melibatkan generasi milenial; (3) dialog, (4) setting/tata panggung; (5) adanya kolaborasi dengan seniman non-drama gong; dan (6) pemanfaatan teknologi digital dalam proses pengemasan dan penyaluran pertunjukan drama gong melalui channel tayangan digital televisi atau Youtube. Disamping bisa menonton langsung secara offline, penggemar drama gong juga bisa menikmati serial pertunjukan drama gong melalui televisi dan Youtube, tanpa dibatasi oleh ruang dan waktu. Keenam inovasi ini membentuk "drama gong model baru" pada era digital atau drama gong inovatif (Sugita, 2021).

Produk drama gong inovatif masa kini antara lain diwakili oleh kisah "Jayaprana" garapan Sanggar Kayon Gianyar dan Sekdut Denpasar yang ditayangkan Bali TV (2020), serta kisah "Ni Diah Tantri” dan "Cupak Madeg Ratu” garapan Sanggar Seni Puspa Kencana (SSPK) Denpasar yang ditayangkan TVRI Bali (2021). Substansi ketiga kisah drama gong ini dapat dideskripsikan secara singkat pada Tabel 1.

Tabel 1

Substansi Kisah Jayaprana, Ni Diah Tantri dan Cupak Madeg Ratu

\begin{tabular}{|c|l|}
\hline Kisah & \multicolumn{1}{c|}{ Substansi (Intisari) } \\
\hline Jayaprana & $\begin{array}{l}\text { Kisah tentang kesetiaan pasangan suami istri “Jayaprana-Layonsari” } \\
\text { dan kesewenang-wenangan penguasa (Raja) yang bertindak lalim } \\
\text { kepada rakyatnya (Jayaprana). Sang raja mengutus patih Sawonggaling } \\
\text { melenyapkan nyawa Jayaprana, demi ambisinya untuk merebut } \\
\text { Layonsari (istri Jayaprana). }\end{array}$ \\
\hline Ni Diah Tantri & $\begin{array}{l}\text { Sebuah kisah tentang seorang raja yang gemar berbuat mesum, dan } \\
\text { telah banyak menelan korban gadis di lingkungan kerajaannya. Tabiat } \\
\text { bejat yang suka bermain perempuan ini pun berakhir, setelah raja } \\
\text { bertemu dengan Ni Diah Tantri, yang akhirnya dipersunting sebagai } \\
\text { permaisurinya. }\end{array}$ \\
\hline Cupak Madek & $\begin{array}{l}\text { Kisah tentang dua bersaudara yaitu Cupak (yang culas, jahat) dan } \\
\text { Gerantang (yang jujur, baik). Cupak yang ambisi jadi raja, tetapi } \\
\text { dengan jalan curang terhadap saudaranya Gerantang. Si Gerantang } \\
\text { sebagai simbol kejujuran dan kebenaran akhirnya menang terhadap } \\
\text { kejahatan (si Cupak). Akhirnya si Gerantang hidup mulya, sebaliknya } \\
\text { si Cupak hidup sengsara, diusir dari kerajaan Kediri. }\end{array}$ \\
\hline
\end{tabular}

Sumber: Diolah dari Sinopsis (Sugita, 2021).

Secara umum kisah "Jayaprana", "Ni Diah Tantri” dan "Cupak Madeg Ratu" merupakan kisah kemanusiaan antara kebenaran dan kebatilan (kejahatan). Ketiga kisah drama gong tersebut mencerminkan tentang ketidakseimbangan hubungan antarsesama manusia (pawongan). Ada pihak yang dikorbankan - seperti nasib kematian "Jayaprana" yang mengundang simpati dari penonton drama gong. Tiga kisah drama gong tersebut merupakan cerminan konflik manusia yang lebih bersifat batin dari pada fisik. Konflik yang dipaparkan dalam lakon drama gong selalu memiliki motif dan konflik. Lakon yang dibangun itu diwujudkan dalam bentuk kejadian-kejadian yang wajar dan realitas, artinya benar-benar diambil dari kehidupan manusia. Seluruh perjalanan drama dijiwai oleh konflik pelakunya. Konflik itu terjadi oleh pelaku yang mendukung cerita. Mereka sering disebut pelaku utama yang bertentangan dengan pelaku pelawan arus cerita (pelaku penentang). Dua tokoh tersebut masing-masing disebut tokoh protagonis dan tokoh antagonis. Konflik kedua 
tokoh itu diekspresikan sedemikian keras, tetapi wajar, realistis, dan logis (Waluyo, 2002: 4).

Sebagai seni tradisional Bali lainya, tiga kisah drama gong "Jayaprana", "Ni Diah Tantri", dan "Cupak Madeg Ratu" adalah tontonan sekaligus tuntunan, menyampaikan pesan-pesan pembangunan dan kritik sosial yang dibingkai dengan candaan, sindirian dan humor yang lucu. Sesuai teori semiotika dan interaksionisme simbolik, suatu tanda, simbol, adegan atau apapun yang muncul dalam pentas drama gong adalah media edukasi yang akan ditangkap dan direspon oleh penontonnya (Riyadi, 2001; Sobur, 2004). Disamping menghibur penggemarnya, tiga kisah drama gong ini juga menyampaikan edukasi nilai-nilai budaya, khususnya filosofi Tri Hita Karana (THK). Disamping melalui tokoh utama, pesan edukasi drama gong juga disampaikan oleh para punokawan yang berperan sebagai parekan (abdi) penasihat, pelawak, maupun komentator (Atmaja, 1988). Drama gong mengajarkan tentang nilai-nilai filosofi THK, yakni sikap hidup yang seimbang antara memuja Tuhan dengan mengabdi pada sesama manusia, serta mengembangkan kasih sayang pada sesama manusia serta mengembangkan kasih sayang pada alam lingkungan (Gambar 1).

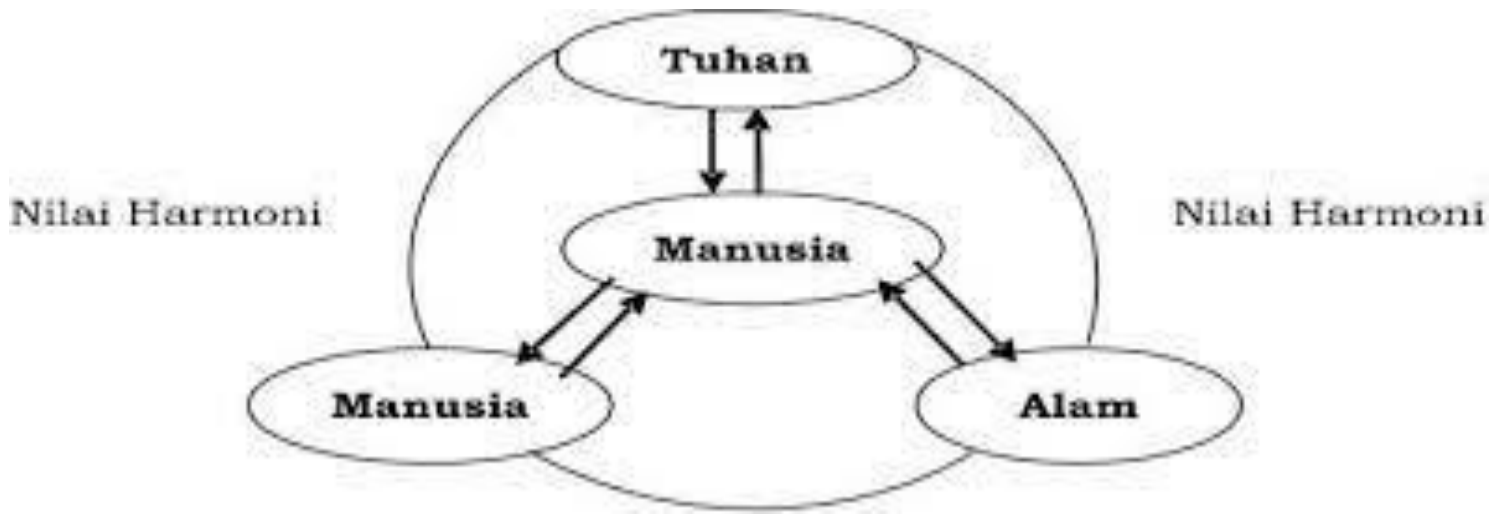

Gambar 1: Tiga Dimensi Filosofi Tri Hita Karana

Filosofi Tri Hita Karana menjiwai napas kehidupan orang Bali (Hindu) dan menjadikan Bali Harmonis baik secara makrokosmos maupun secara mikrokosmos (Purana, 2016). Pertama, pertunjukan drama gong memberikan edukasi tentang prinsip parahyangan. Hal ini secara langsung tervisualisasi melalui tindakan segenap pendukung drama gong yang menjunjung tinggi nilai-nilai religius dan menyadari akan keberadaan Sang Pencipta. Mereka berupaya memberikan persembahan (bhakti) lewat karya dan ekspresi seninya yang penuh dengan nilai religius. Sebelum pementasan di mulai para pemain Drama Gong melakukan persembahyangan memohon kelancaran dalam pementasan Drama Gong kehadapan Ida Sang Hyang Widhi Wasa dalam wujud Sang Hyang Taksu (Tabel 2).

Tabel 2

Edukasi Tri Hita Karana Dalam Drama Gong

\begin{tabular}{cl}
\hline $\begin{array}{c}\text { Parahyangan } \\
\text { (hubungan manusia } \\
\text { dengan Tuhan) }\end{array}$ & $\begin{array}{l}\text { - Ajaran untuk selalu berhakti kepada Hyang Widi Wasa } \\
\text { - Perlunya manusia menyadari akan adanya karmapala } \\
\text { - Kesadaran atau pengakuan manusia akan perbuatan } \\
\text { kesalahannya } \\
\text { - Upaya untuk bertobat dan menjalin hubungan harmonis } \\
\text { dengan Tuhannya. }\end{array}$ \\
\hline $\begin{array}{c}\text { Pawongan } \\
\text { (hubungan antar sesama } \\
\text { manusia) }\end{array}$ & $\begin{array}{l}\text { Ajaran untuk selalu berbuat baik (dharma) kepada } \\
\text { sesama, serta menghindari periaku adharma yang } \\
\text { merugikan orang lain }\end{array}$ \\
\hline
\end{tabular}


- Cinta kasih dalam kehidupan keluarga/masyarakat

- Saling hormat menghormati dalam kehidupan

bermasyarakat, saling bertolerasi terhadap sesama warga sebangsa.

$\begin{array}{cl}\text { Palemahan } & \text { - Ajaran untuk selalu merawat dan melestraikan alam } \\ \text { (hubungan manusia } & \text { - Selaras dan menjaga keasrian dan kelestarian lingkungan } \\ \text { dengan lingkungan } & \text { hidup } \\ \text { hidup } & \text { - Menjaga Bali sebagai Pulau Taman }\end{array}$

Sumber: Diolah dari data lapangan (Sugita, 2021)

Pertunjukan drama gong memberikan contoh tentang ajaran karmapala. Siapa mananam kebaikan ia akan menuai kebaikan itu, sebaliknya siapa berbuat kejahatan ia pun memetik hasilnya. Dalam kisah Cupak Madeg Ratu garapan Sanggar Seni Puspa Kencana (SSPK) Denpasar yang ditayangkan TVRI Bali (2021) misalnya, hal ini tercermin pada nasib mujur Gerantang yang berbuah manis - memperoleh kemulyaan di kerajaan Kediri, sebaliknya si Cupak yang sering melakukan perilaku adharma, penuh tipu daya akhirnya juga menerima akibat perbuatannya.

Kedua, drama gong juga memberikan edukasi tentang prinsip pawongan, hubungan sosial manusia yang harmonis dengan sesamanya. Hal ini secara nyata dicerminkan dalam hubungan sosial antar pendukung seni drama gong. Beragam pelaku seni: penari, penabuh, koreografer, tim penunjang lainnya bisa bekerjasma dan berkolaborasi secara harmonis sehingga seni pertunjukan drama gong dapat digelar. Pelaksanaan pementasan drama gong adalah pertunjukan yang bersifat sosial. Segenap pendukung drama gong selalu merasakan adanya ikatan kebersamaan baik selama latihan, maupun saat pertunjukan. Perbedaan golongan dan status tidak menjadi penghalang dalam berinteraksi, saling tukar menukar pengalaman. Latar belakang pendidikan, pekerjaan dan tempat tinggal yang berbeda-beda, mewujudkan interaksi atau hubungan yang lebih akrab dan penuh dengan nuansa kekeluargaan (Widagama, 2017).

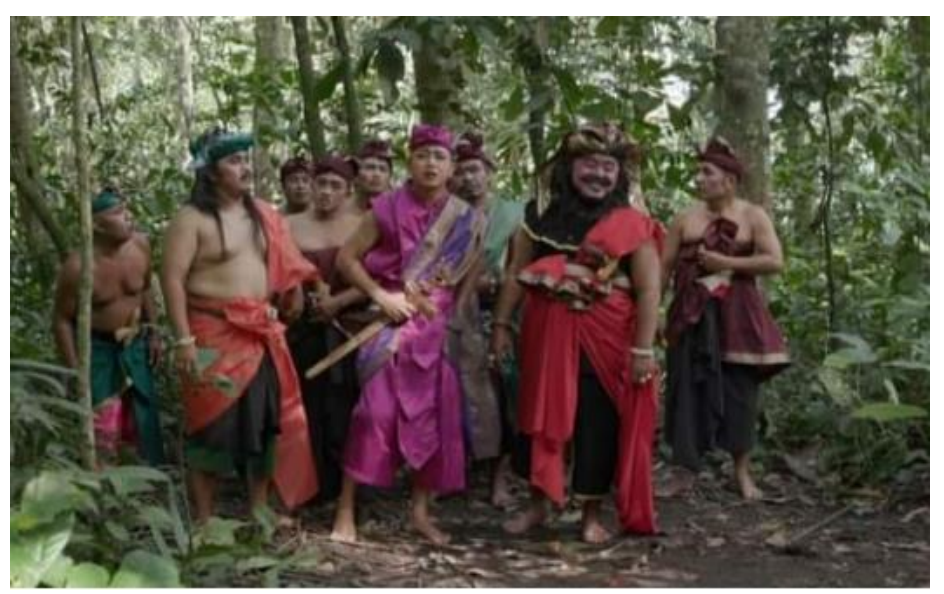

Gambar 2

Adegan Patih Sawonggaling dan pengikutnya saat akan membunuh Jayaprana (Sumber: Dokumentasi Penulis)

Ketiga, drama gong memberikan edukasi tentang prinsip palemahan, yakni ajaran untuk selalu merawat dan melestarikan alam, bersikap selaras dan menjaga Bali sebagai Pulau Taman. Bali layak disebut Pulau Taman karena memang tersusun oleh banyak taman, baik yang bersifat alami seperti: taman pantai, taman danau, taman pegunungan, taman tebing, dan taman lembah, maupun taman buatan seperti: taman situs budaya peninggalan 
kerajaan (seperti: Taman Ujung, Taman Tirta Gangga, Taman Kertha Gosa, Taman Tirta Empul, Gunung Kawi, Goa Gajah, Taman Ayun, dan ribuan Pura Taman/Pura Beji yang ada di setiap desa pekraman serta taman keluarga yang ada di setiap pekarangan di Bali (Sugianthara, 2015).

Dalam pertunjukan drama gong dengan kisah Jayaprana (2020), disosialisasikan visi Pemerintah Provinsi Bali “Nangun Sat Kerthi Loka Bali” yakni upaya menjaga kesucian dan keharmonisan alam Bali beserta isinya untuk mewujudkan kehidupan krama Bali yang sejahtera dan bahagia. Menuju Bali Era Baru dengan menata secara fundamental dan komprehensif pembangunan Bali yang mencakup tiga aspek utama yakni alam, krama dan kebudayaan Bali berdasarkan nilai-nilai THK yang berakar dari kearifan lokal Sad Kerthi (Pemda Bali, 2020). Kekayaan sumber daya alam perlu dikelola secara manageable, termasuk menjaga potensi - ketersediaan sumberdaya energi alam Bali yang meliputi apah (air), teja (sinar), bayu (angin), akasa (eter) dan pertiwi (tanah), yang dikenal sebagai Panca Maha Butha. Konsep Tri Hita Karana yang sudah diadopsi oleh UNWTO dan Sustainable Development Program ini, secara universal dimaknai sebagai sistem budaya, sistem sosial dan sistem lingkungan (Yudiata, 2000).

"Jayaprana", "Ni Diah Tantri" dan "Cupak Madeg Ratu" adalah bagian dari kisah yang menyampaikan edukasi THK kepada masyarakat Bali, penggemar drama gong. Edukasi tentang THK tersebut dilakukan berupa "contoh perilaku" baik yang perlu wajib ditiru atau yang wajib ditinggalkan. Ajaran karmapala dalam kisah Cupak Madeg Ratu misalnya adalah pelajaran bahwa orang yang rajin dan jujur, berperilaku baik akan sukses dalam hidunya di kemudian hari seperti Gerantang yang mendapat kemuliaan di kerajaan Kediri. Sebaliknya perilaku malas, suka menipu, merugikan orang lain akan berbuah celaka seperti cupak yang akhirnya bernasib sial, diusir dari kerajaan Kediri. Diharapkan, melalui pesan tersurat dan tersirat penggemarnya menjadi masyarakat pintar sesuai era 5.0, mampu mewujudkan kehidupan yang harmonis: antara manusia dengan Tuhan (parahyangan), manusia dengan sesamanya (pawongan), dan manusia dengan alam (palemahan).

\subsection{Edukasi Tri Hita Karana Drama Gong: Penapang Keberlanjutan Budaya Bali}

Tiga kisah drama gong, yaitu "Jayaprana" ditayangkan Bali TV (2020/2021), serta "Ni Diah Tantri" dan "Cupak Madeg Ratu" ditayangkan TVRI Bali (2021) merupakan bentuk drama gong inovatif - yang memberikan edukasi budaya Bali, khususnya tentang filosofi THK kepada penggemarnya di era society 5.0 dewasa ini. Drama gong inovatif pada era digital dewasa ini telah menyertakan generasi milenial sebagai pemainnya. Ini berarti telah terjadi proses pewarisan seni budaya (drama gong) dari generasi ke generasi berikutnya. Sebagian generasi millennial Bali menikmati tontonan drama gong melalui gadget (handphone) mereka. Hal ini sesuai dengan era society 5.0 yang menuntut semua orang untuk memanfaatkan teknologi digital secara cerdas. Anak-anak millennial Bali tidak hanya memakai handphone untuk mengakses hibran modern seperti music, film dan game online saja, tetapi juga memanfaatkannya untuk menikmati sajian tayangan "drama gong" via Youtube.

Proses pewarisan seni budaya dapat berlangsung melalui proses pembelajaran secara formal dan informal. Proses pembelajaran formal berlangsung sejak anak-anak di bangku taman kanak-kanak sampai perguruan tinggi (PT), sedangkan proses pendidikan informal berlangsung melalui enkulturasi (pembudayaan) dan sosialisasi di lingkungan keluarga. Seperti kata Anthony Gidden (2003), peran orangtua (orang dewasa) begitu penting untuk melakukan sosialisasi dan enkulturasi (proses pembudayaan) nilai-nilai budaya kepada anak-anak selaku generasi penerus. Sesuai teori tindakan sosial Bourdieu (1990), sejak dini anak-anak Bali diharapkan memiliki habitus (struktur mental) dan kesadaran diri untuk mencintai budaya leluhurnya. Upaya mengajak anak-anak millennial Bali menjadi penerus 
seni pertunjukan drama gong adalah langkah yang strategis untuk menyelamatkan keberlanjutan "seni pertunjukan" ini.

Drama gong juga menjadi media yang efektif dalam penyampaikan edukasi tentang filosofi THK kepada penggemarnya. Filosofi THK pada dasarnya adalah sebuah landasan yang bersumber dari ajaran agama Hindu, namun sejatinya THK merupakan filosofi universal berlaku dalam semua aspek kehidupan umat manusia. Filosofi THK mengedepankan harmoni dan prinsip-prinsip kebersamaan dalam kehidupan umat manusia. Hidup harmoni di tengah-tengah suasana kebersamaan yang tulus dan murni, menjadi idaman setiap manusia di manapun berada, tanpa membedakan aliran ataupun kepercayaan (Windia , 2005).

Filosofi THK bisa diartikulasikan kembali melalui seni pertunjukan drama gong inovatif. Hal ini sejalan dengan upaya penguatan identitas kultural masyarakat Bali lainnya, termasuk penguatan kembali Hinduisme dengan penggunaan bahasa daerah Bali, berbusana tradisional Bali, bersikap dan bertindak sesuai ajaran agama Hindu, menghidupkan konsep tata ruang ala Bali, serta mengangkat kembali beragam kesenian dan tradisi yang diakui sebagai bentuk revitalisasi budaya Bali (Lubis, 2007). Selanjutnya, Edukasi THK melalui pertunjukan drama gong diharapkan mampu menggugah kepedulian dan partisipasi masyarakat Bali dalam menegakkan ajaran THK yang mendukung upaya penyelamatan tradisi dan keberlanjutan budaya masyarakat Hindu Bali.

\section{SIMPULAN}

Drama gong merupakan salah satu seni pertunjukan tradisional Bali berfungsi sebagai media hiburan dan media edukasi budaya Bali, khususnya tentang filosofi Tri Hita Karana kepada penggemarnya. Melalui tiga kisah drama gong, yakni "Jayaprana", "Ni Diah Tantri" dan "Cupak Madeg Ratu" telah berhasil menghibur sekaligus menyampaikan edukasi Tri Hita Karana (THK), agar masyarakat Bali mampu mewujudkan kehidupan yang harmonis: antara manusia dengan Tuhan (parahyangan), manusia dengan sesamanya (pawongan), dan manusia dengan alam (palemahan). Edukasi THK melalui pertunjukan drama gong memiliki makna dalam memperkuat tradisi dan menopang keberlanjutan budaya masyarakat Hindu Bali. Pengembangan seni pertunjukan drama gong yang mampu memperkuat identitas kultural masyarakat Hindu Bali perlu dikembangkan.

\section{DAFTAR PUSTAKA}

Atmaja, Jiwa. 1988. Tri Dasa Warsa Teater Mini Badung. Denpasar. Udayana University Press.

Bourdieu, Pierre. 1990. (Habitus X Modal) + Ranah= Praktik : Pengantar Paling Komprehensif kepada Pemikiran Bourdie. Bandung: Jalasutra. Sumber terjemahan An Introduktion to the work of Pierre Bourdie: The Practice Theory. Editor Richard Harker. 1990. The Macmillan Press Ltd: London.

Dibia, I Wayan. 2012. Geliat Seni Pertunjukan Bali. Denpasar: Arti Foundation

Giddens, A. 2003. The Constitution of So-ciety : Teori Strukturasi untuk Analisis Sosial (D.

A. L. Sujono, Trans.). Pasuruan: Penerbit Pedati.

Hasan, Fuad. 1980. Humor dan Kepribadian. Makalah Seminar

I-Scoop. 2018. Industry 4.0: the fourth industrial revolution - guide to Industrie 4.0. Diambil 4 Maret 2018, dari https://www.i-scoop.eu/industry-4-0/

Kartodirdjo, Sartono. 1973. Protest Movement in Rural Java: A Study of Agrarian Unrest in the Ninenteenth Centuries, Singapore: Oxford University Press.

Lubis, Devy N. 2007. Identitas Kultural Bali di Bali TV : Studi Analisis Wacana Bali TV Sebagai Wadah Identitas Kultural Bali dalam Program Acara Berita Bali TV 
dengan Pendekatan Cultural Studies. Skripsi thesis, Universitas Airlangga, http://repository.unair.ac.id/18129/)

Mantra, Ida Bagus. 1996. Landasan Kebudayaan Bali. Denpasar: Yayasan Dharma Sastra.

Nastiti, Faulinda Ely, Aghni Rizqi Ni'mal 'Abdu. 2020. Kesiapan Pendidikan Indonesia Menghadapi era society 5.0; Edcomtech, Jurnal Kajian Teknologi Pendidikan, Volume 5, No 1, April 2020, 61-66.

Pemda Bali, 2020. Program "Nangun Sat Kerthi Loka Bali" Mewujudkan Bali Era Baru; https://nangunsatkerthilokabali.com/program-nangun-sat-kerthi-loka-balimewujudkan-bali-era-baru/

Peraturan Daerah Provinsi Bali Nomor 5 Tahun 2020 Tentang Standar Penyelenggaraan Kepariwisataan Budaya Bali

Purana, I Made, M.Si. 2016. Pelaksanaan Tri Hita Karana Dalam Kehidupan Umat Hindu, Jurnal Kajian Pendidikan Widya Accarya FKIP Universitas Dwijendra, Maret 2016.

Riyadi, Soeprapto. 2001. Interaksionisme Simbolik (perspektif sosiologi modern. Malang: Averroes Press.

Ruastiti, Ni Made. 2020. Strategi Pembangunan seni-Budaya Pada Era Digital (Orasi Ilmiah). Jayapura: ISBI Tanah Papua.

Setyawan, Arya Dani. 2011. "Fungsi Seni Pertunjukan Tradisional"; http://aryadanisetyawan.blogspot.com/2011/11/fungsi-seni-pertunjukantradisional-di.html. Diakses 24 September 2021.

Sugita IW, Setini M, Anshori Y. 2021. Counter Hegemony of Cultural Art Innovation against Art in Digital Media. Journal of Open Innovation: Technology, Market, and Complexity. 2021; 7(2):147. https://doi.org/10.3390/joitmc7020147

Sugita, I Wayan. 2017. Pasang Surut Pementasan Drama Gong di Bali: Faktor Penyebab dan Implikasinya. Denpasar: Sekdut Bali Performing Arts Community.

Sugita, I Wayan. 2020. Drama Gong sebagai Media Pendidikan dan Kritik Sosial, Jurnal Kajian Bali, Vol 10 No 2 (2020), https://ojs.unud.ac.id/index.php/kajianbali.

Sobur, Alex. 2004. Analisis Teks Media. Bandung: PT Remaja Rosdakarya.

Sugianthara Anak Agung Gede. 2015. Implementasi Tri Hita Karana Dalam Pengelolaan Lingkungan Hidup di Bali Dalam Menjaga Eksistensi Bali Sebagai Pulau Taman. Denpasar: Program Studi Arsitektur Pertamanan Fakultas Pertanian Universitas Udayana.

Undang-Undang Nomor 5 Tahun 2017 tentang Pemajuan Kebudayaan

Waluyo, Herman. 2002. Drama, Teori dan Pengajarannya. Yogyakarta: Hamindita Graha Widya.

Windia,W. 2005. 'THK dan Pariwisata Berkelanjutan”, dalam Buku Panduan THK Awards andAccreditation tahun 2005, Green Paradise, Denpasar.

Widagama, Ngakan Putu Gatam. 2017. Pementasan Drama Gong Wijayakusuma Sebagai Media Komunikasi Tradisional Di Kelurahan Abianbase Kecamatan Gianyar Kabupaten Gianyar. Jurnal penelitian Agama Hindu, Vol 1, Nomor 2, Oktober 2017.

Yudiata, KW. 2000. "Tranformasi Konsep Tri Hita Karana dari Nilai Ideal, Melalui Nilai Instrumetal, Menuju Nilai Praksis", Handbook of Tri Hita Karana Tourism Award and Accreditation. Denpasar: Bali Travel News, Kemenbudpar, Kementerian Lingkungan Hidup.

Yusuf, Himyari. 2015. Kebudayaan Nasional Dan Ketahanan Bangsa, Meneropong Jiwa Nasionalisme Masyarakat Kontemporer ; Jurnal TAPIs Vol.11 No.2 JuliDesember 2015. 